\title{
One for All, All for One - Performing Citizen Driven Development of Public E-Services
}

\author{
Katarina L. Gidlund \\ Department of Information technology and media \\ Mid Sweden University \\ SE-851 70 Sundsvall \\ Sweden \\ katarina.lindblad-gidlund@miun.se
}

\begin{abstract}
The notion of citizen driven development of public e-services has been vivid for a number of years in eGovernment research, practice and policies. A variety of expectations are coupled with the idea of citizens participating in the development process; ranging from, roughly outlined, more efficient services (economic gain and customer satisfaction) and enhanced democracy (deliberation and empowerment). There are less conceptual analyses resting on a critical stance analysing how this notion is translated in practical settings, leaving a gap in between for practitioners to solve. This paper presents explorative work made in a Swedish authority, setting out to understand their structure, and the available methods used, in relation to the concept. The results show that besides difficulties in creating systematic work processes, what surfaces is the complex task of estimation.
\end{abstract}

Keywords: eParticipation, citizen driven, participation, development, public eservices, analysis of concepts, estimation.

\section{Introduction}

The European eGovernment Action Plan 2011-2015 [1] stress, as several earlier documents have, the imperative of "involving users actively in design and production of eGovernment services" [1 p.7]. Throughout the document the notion of participation is repeated over and over again in different shapes: involvement, empowerment, collaboration, flexible and personalized, user satisfaction etc. From reasoning it is understood that participation is perceived as fundamental. Descriptions of why and how is though not that present, besides the statement early in the document saying that; "the majority of EU citizens are reluctant to use them [the public e-services]" [1 p. 3] generating a strong need to "move towards a more open model of design, production and delivery of online services, taking advantage of the possibility offered by collaboration between citizens, entrepreneurs and civil society" [1 p. 3]. So, the logic being that the citizens would use the e-services if they could be part of their creation, why so is not elaborated upon. The underlying reason for the existence of e-services at all is though that they can "help the public sector develop innovative ways of delivering its services to citizens while unleashing efficiencies and 
driving down costs" [1 p.3]. The relation between these two statements and their interdependent logic, citizens would use the e-services if part of their creation and eservices would enhance service delivery and drive down costs, is however not further problematised. Thus, their intersection is highly interesting and stress other questions such as; resistance among administrative personnel in fear of losing their employment, or resistance by citizens for carrying out the administrative work of the government employees already paid for in terms of taxes, or, where the added service value appears if you perform the administration yourself [2].

The notion in itself, of citizen driven development (which will be the wording used in this paper), is though existing in many contexts; in policies, in research and in practice. For example in public administration and political science as 'new governance' and 'citizen participation' addressing issues of quasi-legislative and quasi-judicial governance processes as deliberative democracy, e-democracy, public conversations, participatory budgeting, citizen juries, study circles, collaborative policy making etc. in order to permit citizen and other stakeholders to actively participate in the work of government [3]. Some more related to input on how to improve the quality in administrative work whereas some refer to facilitating active political involvement of the citizenry (different themes of so called deepening democracy) [4, 5]. In the IS community as 'eParticipation' with concerns such as; how to accumulate needs and preference, how to ensure cohesion across processes and how to select tools and methods, how to secure interactivity and scalability and how to evaluate impact [6]. Generally resting on a focus on liberal collaborative forms of participation which could rather be defined as some form of consultation than a more direct form of democracy $[7,8]$.

In this paper the focus is thus directed more closely on how the notion of citizen driven development then could be performed, that is, not why citizens should participate but how, and how their participation could be taken care of in government. If citizen participation is an imperative from the European Commission it ought to be translated and enacted on a national level throughout public sector [9]. The point of departure for the analysis at hand is therefore that of a critical analysis of concepts i.e. to understand how the notion is 'done' one need to understand how it is translated in the specific context. The final aim being that of by doing so, contribute to the gap in between policy visions and practical undertakings by and large for practitioners to solve. This paper presents explorative work made in a Swedish authority setting out to understand their systematic, and the available methods used, in relation to the notion of citizen driven development of public e-services. As a background the idea of 'participation' is put forward from two perspectives (as a design issue and as a political agenda). Thereafter the critical analysis of concepts as a methodology is explained, the case is described and the results are shown. Finally, in the conclusion the main findings are reflected upon in relation to the background setting.

\section{Participation as a Design Issue}

Since the focus in this paper is on performance, how citizen driven development of public e-services is actually put into practice, the design perspective is imperative in order to understand the actual processes. It should thus be noted that in design practices 
related to the design of information systems (here used as equivalent to e-services) the 'participating user (here used as equivalent to citizen)' holds an almost indisputable position. Already in 1984 Ives \& Olson [10] made a literature review touching upon user involvement and indicators of system success, and since then many others have followed; Kappelman \& McLean [11]; Hartwick \& Barki [12]; Iivari \& Igbaria, [13], among others. In these studies it has for long been claimed that the involvement of appropriate and representative users is critical to the success of a system.

Overall, there has developed several different aspects of the basic notion of a participating user; user participation, prototyping, participatory design (PD), computer supported cooperative work (CSCW), usability engineering, and user-centered design. Sanders and Stappers [14] have, from a design perspective, illustrated the great variety in the landscape of participatory design as ranging from seeing the user as a subject to the user as partner and the process led by design or led by research (se figure 1 below):

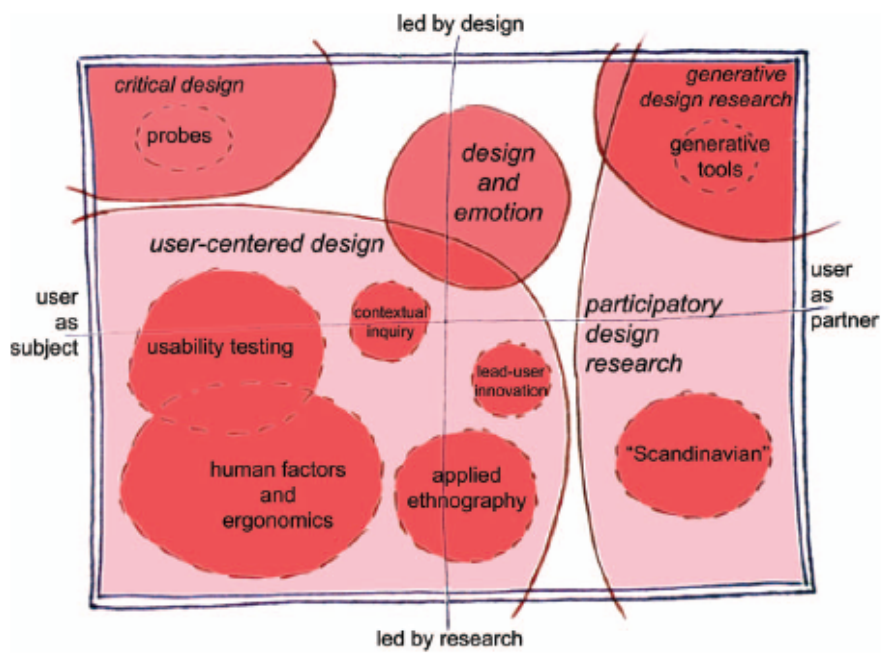

Fig. 1. The current landscape of human-centered design research as practiced in the design and development of products and services

These are all different ways of involving the user in some way, and to some extent and they offer a wide range of techniques on how to do so. Even though they differ with regards to who should be involved, when, and in what role [14]. Thus, taken together they all share the assumption that it is crucial that the voices of the users-tobe are present in the design process. The reasons behind this might vary from democratic reasons, such as work place democracy or counteracting discrimination, to purely economic reasons (i.e. it is necessary to be able to develop a product that will meet a market), and it is notable that there are several differences between them concerning how this should be done and why.

In recent years, another complexity in the notion of a participating user in the design process is however added, the dispersed and unknown users, for example in relation to the shift towards the citizen as user of public e-services. Traditionally, 
most user-focused studies [15] concentrated on the organizational individual since from the beginning the research was aimed at designing technology for workplaces [16]. Work practices and professional use was as such a natural focal point due to the fact that the computer had not yet reached the private sphere to the extent it has today [17]. Moreover, since many systems today are developed for very large user populations (even in some workplace settings), it is hard, not to say sometimes impossible, to involve all users or even to find suitable user representatives, or create fictive users $[18,19]$. To then create a useful set of fictive users or a useful number of representative users, we will have to extract a very large number of heterogeneous characteristics from a very small number of generalized characteristics. Such an extraction, resting on what is considered as important characteristics in the specific situation, might run the risk of losing what really matters during the process because the information is mistakenly perceived as beyond the scope. As Mackay [19] touches upon (which is an interesting distinction related to user participation in IS design); are everybody's insights equally welcome or are there preconceived ideas about what kind of user should be given opportunity to formulate requirements, and who decides who should be listened to? Summing up, existing methodologies and techniques face new challenges and might need adjustment to be developed further in consistency with societal changes.

What is maybe even more interesting is though that the notion of a participating user as such is seldom questioned. As Sanders and Stappers state; "It is interesting to note that participation in the design process, as it is practiced today, is focused more on the exploration and identification of presumably positive future opportunities than it is on the identification and amelioration of adverse consequences" [14 p.8].

\section{Participation as a Symbolic Political Construct}

There are some interesting voices raised addressing the perceived shift in several policy settings towards emphasizing 'users' as an increasingly vital actor, Shove and Rip [20] being one of the most interesting ones. Even though the context of their argumentation is research policy and the considerable emphasis on users as important in order to determine relevance and suitable funding projects, the logic is applicable to participatory eGovernment development policy as well, especially from two points of view; the 'taken for grantedness' and the ignorance regarding the details and performance of the inner logic. Or, as Shove and Rip [34] put it, there is an "overreliance on an embodied notion of use and uncritical acceptance of associated pathways of influence" [20 p.175]. This strongly relates to what is stated in the European eGovernment Action Plan 2011-2015 [1]; the strong need for citizen participation in the development of e-services at the same time as "the majority of EU citizens are reluctant to use them [e-services]" [1 p.3]. Shove and Rip raise important questions such as; what is the nature of this relationship and what constitutes participation, who qualifies as a user and what is their role in the process are raised, and argue that there are relatively little systemic discussions of who users are, what they do, how they interact and what it means [20].

They continue by stressing the symbolic function of the notion of the participating user and reflect on the extent to which these rhetorical interpretations mesh with practice; it dominates the rhetoric but not always the reality. As such they do not exist a 
priori but needs to be defined and constructed, and their characteristics heavily depend upon the purposes they are supposed to fulfil (such as for example legitimate particular practices) [20]. Such a point of departure is very rewarding and creates opportunities to reflect upon the symbolic quality of the notion of a participating citizen as well. Show and Rip conclude by stating that the concept of the user is a device for invoking potential value; if the user exists and he or she wants and uses what we produce it is proven to be essentially good. As such it is upheld by both sides (even if there might be hidden reluctance on the side asked to produce the user driven artifacts) in case of a strong political demand. However, in the real world (opposed to the symbolic constructs) the notion of the participating user creates some complexities. First the good users (the influential, interested, involved and powerful) are in absolute minority leaving it to be hard work for practitioners to actually find them. Secondly, it is easy to go astray and create mythical users, created for rhetorical purposes, and risking to lose track of the real ones. Giving that, proposals may go forward and priorities may be adjusted, to the needs of the mythical user. Thirdly, being a user is not a stable position and efforts to embody the process of use are easily misguided.

Applying their analysis on the notion of a participating citizen in the development of public e-services creates equally interesting thoughts; who qualifies as a citizen, how are we to find among them the citizen interested in participating, if we find someone qualified and interested how are we supposed to interact with them, what is the nature of our interaction, how do we constitute what is labelled as participation or not. Fischer [21] raises these questions in a governmental setting by addressing the cultural politics of discursive space in participatory governance, concerned with the degree to which citizens are able to participate meaningfully and the implications for the nature of professional or expert practices. Even if it is not that easy to parallel governance with the design and development of public e-services the question of how participation should be done remains in both cases. In line with Cornwall [22] Fischer then argues, that participatory governance readjust the boundaries between the state and the citizens with the establishment of new places were the participants can engage each other in new ways. From a governance perspective this readjustment of boundaries then asks for a clear understanding and clear rules asking questions such as; "Are the rules governing who gets to speak fair and equally distributed? Is the discussion open? Is the deliberative agenda transparent to all participants, or are particular elements hidden and secretive? To what degree are all participants represented?" [21 p.22]. In governance literature participation is thus not thought of as an easy task and Fischer conclude that: citizen participation, in short, is a complicated and uncertain business that needs to be carefully thought out in advance [21]. To be aware of the complexity and to deal with it carefully is central, again stressing issues of representation, the discursive space (who gets to speak and who gets to decide etc.) and the hard task of finding the interested citizens is a reoccurring theme.

\section{Conceptual Disentanglement as a Methodology}

As indicated from the discussion on the notion of citizen driven development above, it is far from consistent or finally defined. The use of wording differs (participation, cooperation, involvement, empowerment, collaboration etc.) and so does also the expected value (enhanced and deepened democracy, improved administrative 
efficiency, and better services etc.). This gives that the notion is hard to grasp, and in line with what several other studies have shown, in strong need of clarification [23]. Not in order to end up with a final and generic definition to be used in every specific context but rather as a critical exploration on how this fuzziness works and extends and some of its consequences, especially to practitioners in public administration.

On a general level the design of the study rests upon the interpretative tradition in IS research $(24,25,26)$ focusing on the complexity of human sensemaking. Complexity in terms of acknowledging conflicting interpretations among stakeholders [see e.g. 26] but also the need of being sensitive to rich, in-depth and idiographic meanings that the participants assign to them. The intent is to increase the understanding of the interpretation process in its natural setting [25]. The ambition is therefore not to gain repeatability or generalisations in a positivistic sense, the value of the results is rather judged in terms of the extent to which it allows others to understand the phenomenon [24].

Second, which is closely related to the above, the study is not guided by any propositions in terms of Cavaye [27] but is strictly explorative and aims at conceptual disentanglement for a richer understanding of the interpretation process. The anticipation is therefore not to create answers to a set of questions but to analyse the phenomenon in its context which might then be used to inform other settings [28, 29, $30,31]$. As such, the aim is to identify the concept's extension in a specific setting [32]. The notion of citizen driven development is seen as "sufficient information about a hypothetical scenario" and the subjects (respondents) are seen as in a position to identify the extension of the concept [32]. The disentanglement of the concept then proceeds in part through consideration of a concept's extension within hypothetical scenarios, noting regularities that emerge and reveal that certain features of the world are highly relevant to determining the extension of the concept and, that other features are irrelevant [32]. According to Chalmers and Jackson,"[w] hat emerges as a result of this process may or may not be an explicit definition, but it will at least give useful information about the features in virtue of which a concept applies to the world" [32]. This means that the empirical material is treated as 'displays of perceptions' [33] or manifestations and not valued in terms of true or false representations, allowing the explorative nature at the same time as linking the assigned perceptions to the structure of the overarching notion of citizen driven development.

Third, the empirical material is gathered through loosely structured interviews and focus groups in a Swedish public authority setting (hence called the SPA). The chosen authority is greatly involved with the asked for national transformation in public sector towards e-governments (both as a member of the national delegation and as the responsible public authority for development initiatives). The SPA is also part of the group of authorities developing the flagship of co-operation, an e-service directed towards the process of business establishment and supporting their administration, were several public authorities have been working together (trying to cope with stovepipes and cultural differences).

We started with initial interviews (4 interviews) with what was considered keyactors from different positions and these respondents were chosen by the executive group and director-general. They were so to speak our guides into the administrative business. These guiding interviews were analysed and we came back to the authority with a request of doing complementary focus group interviews with three distinctive 
groups; the IT-experts, the business experts and a group consisting of people with experience from a specific development project (in this case the co-operative flagship since it was mentioned a lot in the initial interviews). We chose the grouping but the SPA chose the specific participants:

Table 1. The focus group interviews

\begin{tabular}{lll}
\hline & Focus groups & $\begin{array}{l}\text { Number of } \\
\text { persons }\end{array}$ \\
\hline Group A & The "IT-group" (holding positions as IT- 3 \\
experts) & \\
The "Business development group" 7 \\
(holding positions as business \\
development experts) project group" 5 \\
The "Development project \\
(holding positions as heavily involved in \\
a specific development project, besides \\
their regular positions)
\end{tabular}

The semi-structured interview guide for both the initial key guiding actor interviews and the focus group interviews had five themes each holding several sub questions; (i) the source of the notion, (ii) the definition of 'citizen' from the SPA perspective, (iii) the definition of 'public e-service' from the SPAs perspective and (iv) the definition of 'citizens driven development' from the SPAs perspective and finally, (v) the expectations linked to the notion of citizen driven development of public e-services. These interviews were carried out through October-December 2010 and the results were presented to the executive group and director-general in January 2011 and a workshop was held in March 2011 with significant representatives from four different sections at the SPA (the head of the register department, the head of the project office, part of the project team of the flagship project towards business establishment, head of usability issues). Some of the reflections from the presentation and the workshop will also be commented on in the analysis.

\section{Results and Analysis}

The extension of the notion of citizen driven development of public e-services turned out to be complex from several points of view in the SPA. What surfaced quite early in the gathering of empirical data was that the concept 'citizen' was hard to define for the respondents. Of course they knew the official definition but it did not suite their processes, they altered between citizens, businesses, clients and customer and when asked they could not really choose one over the other. They wanted to use all of them and claimed that they needed to refer to a precise context in order to be more specific, but still they were a bit insecure about what was actually referred to. The citizen concept was as such indistinct and multi-facetted and we, as interviewers, had to repeat the whole pile of "citizen/business/client/customer" wording throughout the interviews. As such, channel strategies were brought to the fore, the respondents 
touched upon the fact that they had different strategies to communicate with the "citizen/business/client/customer". They also discussed that sometimes it was just one "citizen/business/client/customer" giving them input on a service performance and how should they then estimate the value of that single input in relation to the total users of their services.

Moreover, how this 'citizen driven development' should be performed were described as rather unsystematic. The respondents did not know of an official strategy or process description. On specific levels they knew of some strategies developed to deal with citizen/business/client/customer input, but they could not derive them to the overarching idea of citizen driven development. Furthermore, the methods of citizen driven development were not that clear or manifested but more in terms of 'incoming viewpoints on existing services'. There were not many examples of innovative development co-operations with "citizens/business/client/customers", mainly because they thought it to be difficult and they did not really know how to deal with that kind of input. This invoked discussions on a need to distinguish between improvements of existing services and completely new development, innovation from scratch demands other processes, competencies and channel strategies and also touched upon complex issues of rules and regulations.

Regarding the source of the notion of citizen driven development of public eservices, the respondents referred back to 'some official document' but could not point to a specific document. The reason for pursuing a citizen driven development of e-services were though often referred to as that of a 'customer focus'; we (the SPA) exist for the customers so they should have a saying. So the reason for the SPA was that of being customer-oriented. However, most of them could not really explain the actual driving forces even though they thought it to be important. Of course, it was rewarding with input in order to develop the SPA further but they did not really link that to their individual work processes.

Taken together, the disentanglement of the notion of citizens driven development of public e-services, first in terms of separating the different parts of the concept (citizen, driven, development, e-services) and then in terms of the extension of the parts displayed several interesting gaps (se figure 2 below):

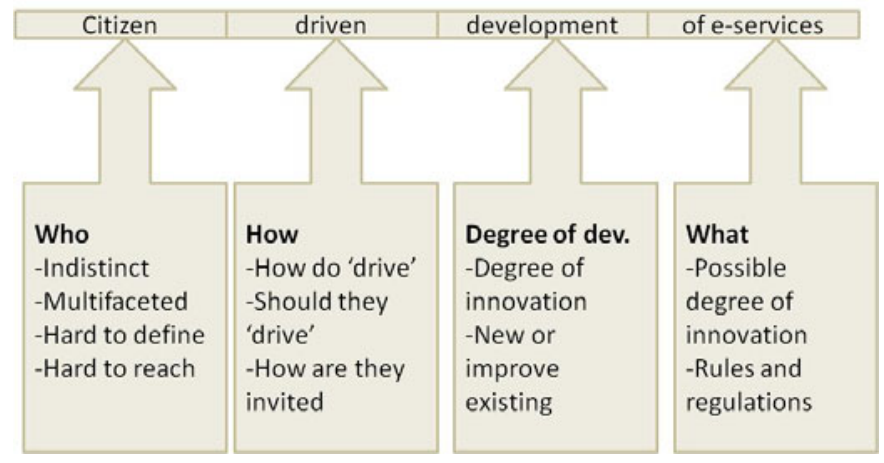

Fig. 2. The extensions of the notion of citizen driven development of e-services 
One interpretation of the above is that of the difficult task for practitioners of deciding on who to listen to and how. If the citizens should be the driving force of part of the development of public e-services how should then the practitioners decide in between the widely dispersed input they get? Should they just count how many has put that exact request forward? And if too few, not consider the input at all? Or the opposite, very many, import and execute the input irrespective of the content? And what is more, should the process of taking input into consideration be the same between proposals for improvement of existing services as proposals for a completely new one?

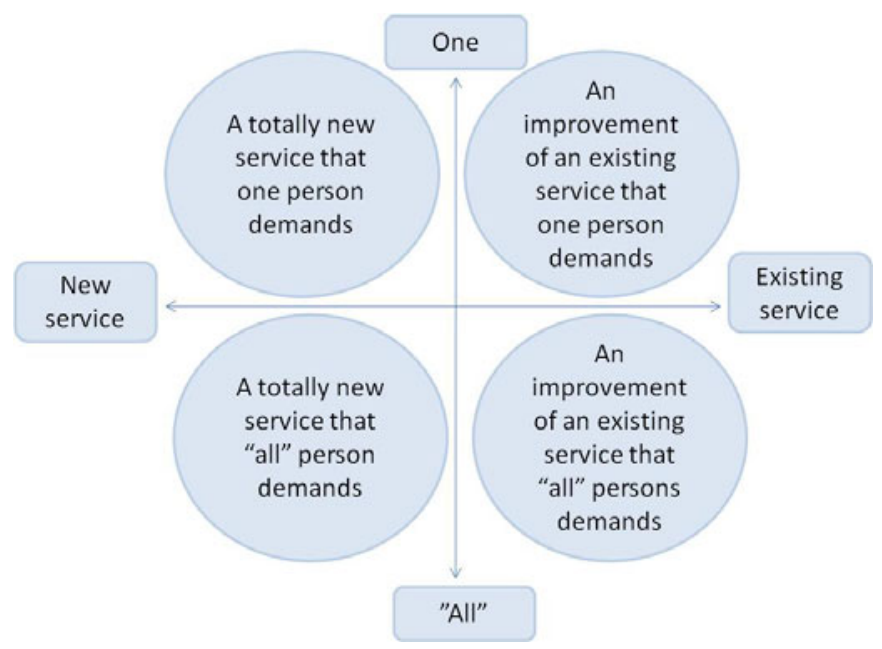

Fig. 3. Processes and method for handling input

The results and the figure (figure 3 ) above were presented to parts of the executive group and director-general in January 2011 and a workshop was held in March 2011 with significant representatives from four different sections at the SPA (the head of the register department, the head of the project office, part of the project team of the flagship project towards business establishment, head of usability issues). Especially the workshop amplified several reflections from the interviews; the difficulties in estimating the value of the diverse forms of input and the lack of the big picture of how the SPA could turn their logic into being more citizen driven in their development processes. The workshop participants stated that the estimation of the value of different forms of input was very dependent on who made the estimation. How the input travelled in the SPA, where it was filtered and by whom. In worst case scenario a really valuable input could actually end up in the garbage can if it got in the hands of the "wrong person". "Wrong" in this respect was versatile, it could mean lack of competence but it could also refer to a situation in the SPA were the person had been going through so many changes lately that he or she could not really absorb yet another suggestion for changes. Moreover, they also touched upon the hard task of estimating how many "citizens/businesses/clients/customers" were needed in order to say that the input they got were to be considered as representative. Even if 
constructed, the selection process in gathering of input from the "citizen/business/ client/customer" was hard and they had trouble in getting in touch with representatives that would participate in the design process.

More so, the process of value estimation of input was often based on how the input could create value for the SPA. If it only created value for the "citizen/business/ client/customer", and not the SPA, it would hardly survive the selection process. There were some exceptions where they could focus on customer value only, but most often the estimation were done with a SPA focus in mind. The perfect match was then when the input and asked for development created value for the customer and the SPA at the same time, these situations were talked about as win-win situations. In these discussions they also reflected upon that importance of the business ratios, if they were directed mainly toward internal efficiency, other initiatives were downsized in competition for development resources.

The SPA is in this respect not unique. On a specific level related to more distinctive activities there exists knowledge on how to deal with input (both in respect to traditional customer service and design techniques to develop IT-based services). But the notion of 'citizen driven development of public e-services' forms a whole that transgress many of these known processes and methods. It transforms the relation between "citizen/business/client/customer" and the public authority and it is supposed to influence and reshape the public sector profoundly. The question however remains on how this should be done in a holistic manner and the systematics of the combination of all these different methods, processes and techniques were absent.

\section{Conclusions: The Complex Chore of Estimation}

This paper started out with the aim of taking a closer look on how the notion of citizen driven development of public e-services is performed; the conceptual extensions and locally situated manifestations. In line with Sanders and Stappers [14] the hypothetical contribution being that of identification and amelioration of adverse consequences, and not only exploring and identifying presumably positive future opportunities. The chosen methodology of conceptual disentanglement (as in identifying extensions of the concept, noting regularities and reveal relevant features) drew attention to two central themes; representativeness and estimation and they, in different ways, surfaced throughout the study. The picture evolving is that of an overreliance and an uncritical acceptance of the notion of citizen driven development of public e-services that fails the practitioners. The results highlights Shove \& Rip's [20] statement that there is a need for systemic discussions of who users are, what they do, how to interact with them and especially what it means (expectations and the possibilities to live up to them), in order to deconstruct the taken for grantedness of the notion of user involvement and deal with the ignorance regarding the details and performance. It is evident that this leaves the practitioners to solve a number of dilemmas and the symbolic function of citizen driven development add to the confusion and hides the need of support for their practical performance. They are in urgent need of critical analyses of how this notion should be performed, presenting guidance through the forest of eye-catching rhetoric. In this study three important knowledge areas evolved; the need to more professional methods in choosing who 
should be acting as filter in order to avoid personal dependence, the need to see the existing methods and techniques in a more holistic process perspective in relation to the goals of the authority, and finally, how to weight the value of the input (value for citizens and/or value for the authority (in this case the SPA).

\section{References}

1. The European eGovernment Action Plan 2011-2015, http://ec.europa.eu/information_society/activities / egovernment/action_plan_2011_2015/index_en.htm (March 3, 2011)

2. Giritli Nygren, K.: "Monotonized administrators" and "personalized bureaucrats" in the everyday practice of e-government: Ideal-typical occupations and processes of closure and stabilization in a Swedish municipality. Transforming Government: People, Process and Policy 4(4), 322-337 (2010)

3. Blomgren Bingham, L., Nabathi, T., O'Leary, R.: The New Governance: Practices and Processes for Stakeholders and Citizen Participation in the Work of Government. Public Administration Review 65, 547-558 (2005)

4. Fung, A., Wright, E.O.: Deepening Democracy: Innovations in Empowered Participatory Governance. Politics \& Society 29(1), 5-41 (2001)

5. Roberts, N.: Public Deliberation in an Age of Direct Citizen Participation. American Review of Public Administration 34(4), 315-353 (2004)

6. Macintosh, A.: eParticipation in Policy-making: the Research and the Challenges. In: Cunningham, P., Cunningham, M. (eds.) Exploiting the Knowledge Economy: Issues, Application, Case Studies. IOS Press, Amsterdam (2006)

7. Sanford, C., Rose, J.: Characterizing eParticipation. International Journal of Information Management 27, 406-421 (2007)

8. Sæbø, Ø., Rose, J., Flak, L.S.: The shape of eParticipation: Characterizing an emerging research area. Government Information Quarterly 25(3), 400-428 (2008)

9. Giritli-Nygren, K., Lindblad-Gidlund, K.: Leaders as mediators of global megatrends - a diagnostic framework. International Journal of Electronic Government Research 5(4) (2009)

10. Ives, B., Olson, M.: User Involvement and MIS Success: A Review of Research. Management Science 30(5), 585-603 (1984)

11. Kappelman, L.A., McLean, E.R.: The Respective Roles of User Participation and User Involvement in Information System Implementation Success. In: Proceedings of Twelfth International Conference on Information Systems, New York, NY, pp. 339-349 (1991)

12. Hartwick, J., Barki, H.: Explaining the Role of User Participation in Information System Use. Management Science 40(4), 440-465 (1994)

13. Iivari, J., Igbaria, M.: Determinants of user participation: a Finnish survey. Behaviour \& Information Technology 16(2), 111-121 (1997)

14. Stappers, E.B.-N., Stappers, P.J.: Co-creation and the new landscape of design. CoDesign 4(1), 5-18 (2008)

15. Bødker, S., Knudsen, J.L., Kyng, M., Ehn, P., Madsen, K.H.: Computer Support for Cooperative Design. In: Proceedings of the 1988 ACM Conference on ComputerSupported Cooperative Work (1988)

16. Iversen, O.S., Kanstrup, A.M., Petersen, M.G.: A visit to the 'new Utopia': revitalizing democracy, emancipation and quality in co-operative design. In: Proceedings of the Third Nordic Conference on Human-Computer Interaction (2004) 
17. Beck, E.E.: P for Political. Scandinavian Journal of Information Systems 14, 77-92 (2002)

18. Rose, D., Blume, S.: Citizens as Users of Technology: An Exploratory Study of Vaccines and Vaccination. In: Oudshoorn, N., Pinch, T. (eds.) How Users Matter, The coconstruction of Users and Technology. The MIT Press, New Baskerville (2003)

19. Mackay, H., Carne, C., Beynon-Davies, P., Tudhope, D.: Reconfiguring the User: Using Rapid Application Development. Social Studies of Science 30(5), 737-757 (2000)

20. Shove, E., Rip, A.: Symbolic Users, Users and unicorns: a discussion of mythical beasts in interactive science. Science and Public Policy 27(3), 175-182 (2000)

21. Fischer, F.: Participatory Governance as Deliberative Empowerment: The Cultural Politics of Discursive Space. The American Public Review 36(19) (2006)

22. Cornwall, A.: Making spaces, changing places: Situating participation in development, Working papers 170. Institute of Development Studies, Sussex, UK (2002)

23. Macintosh, A., Coleman, S., Schneeberger, A.: eParticipation: The Research Gaps. In: Macintosh, A., Tambouris, E. (eds.) ePart 2009. LNCS, vol. 5694, pp. 1-11. Springer, Heidelberg (2009)

24. Walsham, G.: Interpreting Information Systems in Organizations. John Wiley, Chichester (1993)

25. Orlikowski, W., Baroudi, J.: Studying Information Technology in Organizations: Research Approaches and Assumptions. Information Systems Research 2(1) (1991)

26. Klein, H., Meyers, M.: A set of principles for conducting and evaluating interpretive field studies. MIS Quarterly 23, 67-93 (1999)

27. Cavaye, A.L.M.: Case study research: a multifaceted approach for IS. Information Systems Journal 6, 227-242 (1996)

28. Reason, P., Rowan, J.: Human Inquiry: A sourcebook of new Paradigm research. John Wiley, Chichester (1981)

29. Denzin, N.K.: The research act in Sociology: A theoretical introduction to sociological methods. Butterworths, London (1970)

30. Weick, K.E.: Sensemaking in organisations. SAGE Publications, London (1995)

31. Giddens, A.: The Constitution of Society. University of California Press, Berkeley (1984)

32. Chalmers, D.J., Jackson, F.: Conceptual Analysis and Reductive Explanation. Philosophical Review 110(3), 315-360 (2001)

33. Silverman, D.: Interpreting Qualitative Data, Methods for Analysing Talk, Text and Interaction. Sage Publications, London (1993) 